\title{
A Quick fired case-firearm determination from the 102 mass shooting incidents in the U.S.
}

\begin{abstract}
Shooting incidents occur almost daily nationwide. A quick determination of the type of a firearm involved is always a crucial factor for the police to process a shooting scene properly. While such a determination is very important, the literature review indicates a lack of research on the subject. This paper conducted a secondary data analysis of the mass shooting incidents from 1999 to $2015(\mathrm{n}=102)$. Based on ballistic design features, ten categories of fired cartridge cases were collected and analyzed for a quick determination between a fired cartridge case and a firearm. Finally, two image illustrations described how to identify the casing-firearm relationship based on the secondary data analysis. The results of this study may have widespread applications for informing law enforcement officers, first responders, criminal investigators, crime scene technicians, teachers/students ( $\mathrm{K}$ to 12 and colleges), and the general public alike.
\end{abstract}

Keywords: forensic science, firearms examination, fired cartridge case-firearm determination, active shooting scenes, drive-by-shooting, ballistic design features of fired cases
Volume 3 Issue 2 - 2016

\author{
John Zheng Wang \\ Forensic Studies Program, School of Criminology, California \\ State University-Long Beach, USA
}

\begin{abstract}
Correspondence: John Zheng Wang, Forensic Studies Program, School of Criminology, Criminal Justice, and Emergency Management, California State University-Long Beach,
\end{abstract} CA, USA, Tel 562-985-4741, Email zwang2@casulb.edu

Received: November 17, 2016 | Published: December 8, 2016

\section{Introduction}

On June 12, 2016, a mass shooting incident occurred in Orlando, Florida (leaving 50 individuals dead and 53 wounded), making it the deadliest mass shooting in U.S history. The standoff lasted three hours, from 2:02 A.M. to 5:00 A.M., because the SWAT team needed to assess the numbers of shooters and types of firearms involved. Earlier, on December 3, 2015, at 11:00Am, another shooting incident occurred in San Bernardino, California, leaving 14 innocent individuals murdered and 21 wounded. In that incident, police still could not determine the types of firearms encountered even four hours after the incident had begun. In 2015 alone, 52 school-related shootings occurred nationwide: including 21 on college or university campuses, fifteen at high schools, three at middle schools, ten at elementary schools, two at preschools, and one on a school bus. ${ }^{1}$ Of the 52 incidents, suicides accounted for six of the incidents and two for murder-suicides: one occurred on the school bus and the other was a mass shooting with ten death tolls. In the public eye, one doubt has always been cast in nearly every shooting incident: Why arriving police officers did not react more quickly at the scene and save more civilian lives by quickly subduing the suspect(s)? Instead, police usually maintain a standoff for hours before taking any aggressive action. In the public eye, more lives would have been saved had the police reacted quicker.

From the opposite perspective, the police always want the first arriving officers or if possible, the eyewitnesses at an active shooting scene, to first identify and then report immediately the types of firearms involved to the 911 dispatcher and/or the SWAT officers. The responding officers can then make quicker decisions in tactical selections, react more quickly, and reduce the number of casualties. Expressed differently, if someone can identify the types of firearms involved from a fired cartridge case and pass the information along to the police, the police in turn may be quicker in selecting appropriate reactive tactics, thus reducing the stand-off time and maybe saving more lives. The main purpose for this study was to conduct a ballistic analysis of the relationship between the types of fired cartridge cases and the types of firearms involved, helping the police expedite the processing of shooting situations and give more accurate information to the media. A quick determination of fired case-firearm relationship is necessary for three broader practical situations. First, if a citizen finds a fired cartridge case on the ground and is able to report it correctly to the police, the officer may determine the type of firearms and thereby assist in further investigation. Second, at a traditional shooting scene, such as a drive-by shooting or a gun-related crime, crime scene technicians and investigators need to figure out from the fired cases what type(s) of firearms involved. Finally, at an active shooting scene involving hostages, the responding officers desperately need to make a quick determination of what and how many type(s) of firearm(s) are involved in order to handle a shooting situation with proper procedures to avoid unnecessary causalities of both law enforcement and civilians.

This study aimed to expedite the determination of the linkage between fired cases found at the scene and the types of firearms involved. The emphases were:

A. A secondary data analysis of the mass shooting incidents $(n=$ 102) in the U.S. was selected for the most common firearms used (the mode).

B. A purposive sampling of collecting fired cases was employed to associate the types of firearms used in the mass shooting incidents.

C. Two educational illustrations with simple explanations of the fired case-firearm relationship were provided. The two image illustrations have certain utility for law enforcement agencies, school educational programs (for teachers and students), or public awareness campaigns. 


\section{Materials and methods}

The research design or the methodology undertaken consisted of four steps. First, a secondary data analysis was conducted to identify all of the weapons involved from the mass shooting incidents for the staid period ( $\mathrm{n}=102$ incidents) in the U.S. Next, using a cluster sampling methodology, the analysis further classifies the firearms involved into ten model types of fired case-firearm relationships based on ballistic design features. Next, with several field trips a purposive sampling method was employed to collect the ten types of fired cartridge cases from gun stores and shooting ranges. Finally, a ballistic design analysis with identification tips summarizes the key features of each individual type of fired cartridge case-firearm relationship. As a result, two image illustrations were created for the ten types of fired cartridge cases in relation to the ten corresponding types of firearms for law enforcement and for public educational awareness.

\section{Secondary data analysis of the mass shooting incidents}

Many schools provide Emergency Response Guides, emphasizing

1. Evacuate if it is safe

2. Lock the door if possible

3. Fight back with classroom items; and

4. If you must fight, fight to win and survive ${ }^{2}$

While whether or not such counter-measures are feasible or practical, it certainly fails to suggest a critical component: how to educate people at an active shooting scene (e.g. schoolteachers and students) to identify types of firearms involved and pass this information onto the police. Therefore, to become knowledgeable about the common types of firearms used in shooting incidents, a secondary data analysis summarizes the mass shootings from two major documents. First, Analysis of Recent Mass Shooting Incidents provides information on 80 incidents from January 27, 2009 to July $16,2015 .{ }^{3,4}$ Second, Weapons Used in Mass Shooting contains another 22 incidents from April 20, 1999 to February 12, 2010. ${ }^{5}$ With these two major reports, the author was able to know that ten types of firearms were used in the 102 mass shooting incidents in the U.S. and their related background information. The main purpose of this study was to investigate a possible connection between a fired case at the scene and an identification of the type of the firearm(s) involved. Three criteria were chosen to select the samples $(n=102)$ from the two reports. First, only a shooting incident with three or more killed in a single incident qualifies as a sample to fulfill the federal statute in 2012 of "mass shooting incident." Second, the information of the suspect(s) must be available to qualify the legal definition of "case cleared." If the information on suspects is not identifiable, the case should remain as open or "cold" status, thus lacking of validity for this study. Third, the information of specific caliber/gauge on "pistol" "revolver" "rifle" or "shotgun" must be available to qualify for the sampling requirements. Cases with a label of "handgun" were excluded because it can mean either "pistol" or "revolver" because this study focuses on a specific type of fired cases in relation to a specific type of firearms.

\section{Sampling strategies related to the mass shooting incidents}

While the secondary data analysis of the mass shooting incidents $(n=102)$ during quoted time period provides a general background of firearms involved, a cluster sampling of the firearms is necessary to further narrow down the information for a ballistic feature analysis on related fired cases. A cluster sampling methodology divides the firearms from the 102 shooting incidents into ten types based on ballistic functions. A cluster sampling is preferable when "natural" but relatively heterogeneous groupings are evident in a statistical population. In essence, the method divides the population into subgroups, called clusters. Then, the researcher conducts his/her analysis on data from the sampled clusters. In order to cluster, the author made a dozen of field trips to local shooting ranges and gun shops for a better classification. As a result, ten types of firearms from the 102 incidents were clustered:
i. Shotgun
ii. AR rifle
iii. AK rifle
iv. Carbine
v. Pistol
vi. Revolver
vii. O.22 LR
viii. Glock
ix. $\quad 0.357 \mathrm{Sig}$, and
x. Foreign pistols

It is important to note that almost all firearms follow the caliberspecific principle, meaning a specific caliber of firearm is only capable of firing a specifically designed cartridge. Consequently, this principle increases the discrimination power of the study, meaning certain design features of a fired cartridge case can be used to link to a certain type of firearm. Therefore, a fired cartridge case at a shooting scene can indicate a certain type of firearm(s) involved. Once the ten types of firearms were determined, the next step was to collect fired cases to link corresponding types of firearms. A purposive sampling (a non-random sampling method) was used for this purpose. The method is also known as subjective, judgmental, or selective sampling. ${ }^{6}$ When developing a purposive sample, researchers use their special knowledge or expertise about some group to select subjects who represent this population to focus on particular characteristics of a sub-population that are of interest. ${ }^{7}$ Since collecting fired cases from indoor shooting ranges and gun stores in the author's area was more convenient, the author collected or purchased necessary numbers of fired cartridge cases by 16 visits to seven facilities. In each visit, the author asked three questions:

a. Do you have the cartridge cases fired by $\mathrm{X}$ type of firearms?

b. Can I collect or purchase one or two fired cases for my research study?

c. How much can you tell me about the design features of the $\mathrm{X}$ type of fired cases?

\section{Results}

While the general classification of firearms refers to shotguns, rifles, pistols, and revolvers, this study further clusters the firearms from the 102 incidents into ten types of more specific weapons. Moreover, based on ballistic design features of fired cartridge cases, the author collected or purchased ten corresponding categories of fired cartridge cases from the field trips at local gun stores and 
indoor shooting ranges. Next, after observing and examining all the sample-fired cases in the lab, the author successfully identified the ten relationships between the ten categories of fired cartridge cases and ten corresponding ten types of firearms. Finally, based on the lab observations and examinations, the author was able to provide five tables and two illustrations to demonstrate the ten relationships. Specifically, each table offers two pieces of information: a modal category and a percentage of each category of firearms. As a result, the ten relationships between the fired cartridge cases and the firearms in the 102 mass shooting incident from the two major reports in the same duration were presented here.

\section{Summaries on shotguns and rifles in the mass shooting incidents}

The first summary in Table 1 presents four categories of firearms used in the 102 mass shooting incidents (shotguns, AR rifles, AK rifles, and Carbine). While 24 shooting incidents using 12 and 20 gauge shotguns were reported, there were 29 incidents of rifles. The gauge is a special unit used to measure the caliber of all shotgun barrels except 0.410 , which is an inch system. Theoretically speaking, one pound of lead divided equally into 12 units with each unit made into a lead ball corresponds to a ball diameter equal to 0.730 inch and is termed 12 gauge. ${ }^{8}$ Thus, the larger the gauge number, the smaller the ball's size. While the shotgun with a 12 gauge is the most commonly used shotgun (the mode), the other gauges of shotguns (from largest to smallest) are 10, 16, 20, and 28 gauge. For the sake of easy understanding, the rifle consists of four categories. First, the U.S. military-style assault rifle involved the 0.223 caliber cartridge, e.g. the AR-15 were used in the Orlando incident and 11 other times. The 0.223 follows an inch unit system, meaning an inch divided into 100 units leads to 23.3 units corresponding to the diameter of the casing mouth or the bullet diameter. Second, the AK-47 is a military assault firearms that were used 10 times in the incidents. This rifle originated from Russia in 1947 and the casing has the numbers 7.62 x 39 inscribed at the case base where 7.62 refers to the diameter (in $\mathrm{mm}$ ) of the casing mouth or the bullet, and 39 is the length of the casing (in $\mathrm{mm}$ ). Third, the $0.22 \mathrm{LR}$ caliber rifle is the smallest caliber, with a rim-firing system, and is discussed in more detail later in the separate 0.22 LR category. Finally, the carbine is a special rifle with a shorter barrel and lighter weight originally designed for troops to use in tighter quarter scenarios. ${ }^{9}$ There was only a single incident of carbine usage in the 102 incidents. It is important to note that the caliber of a firearm may be expressed either as nominal or specific. While the nominal caliber refers only to a group of firearms, which share the same bore diameter, the specific caliber means a name given to a firearm representing the specifically designed cartridge that fits into the firearm.

Table I Caliber information of shotguns and rifles used in the 102 mass shooting incidents (I999 20I5)

\begin{tabular}{lllllll}
\hline Shotgun (1 2/20 gauge) & Total & Rifle (0.223) & AK47 (7.62 x 39 mm) & Rifle (0.22 LR) & Carbine (0.30) & Total \\
\hline 24 & 24 & $12=$ Mode & 10 & 6 & 1 & 29 \\
\hline
\end{tabular}

\section{Summaries on pistols in the mass shooting incidents}

A semi-automatic pistol is a type of handgun. For civilians, it is required in certain states for a pistol to have a maximum magazine capacity of 10 cartridges. The semi-automatic pistol always requires releasing and pulling the trigger each time to shoot one cartridge. Table 2 introduces information on three categories of pistols based on caliber ballistic features: regular pistols, pistols firing $0.357 \mathrm{Sig}$ caliber cartridges, and pistols made by Glock based on firearmproduced features found on fired casings. Table 2 above shows all the pistols that were used in the 102 mass shooting incidents and presents the sequence in terms of specific caliber from 0.45 to 0.22 (an inch system) and the $9 \mathrm{~mm}$ (a metric system). It is noticeable that the pistol $(9 \mathrm{~mm})$ was the most frequently used firearm or the mode (33 times) while the rest of the frequency of usage is ranked as Pistol 0.45 (16 times), Pistol 0.40 (13 times), Pistol 0.380 (7 times), Pistol 0.22 LR (5 times), Pistol 0.25 (3 time), and Pistol 0.357 (1 times). Examples of pistols chambered in the 0.357 Sig cartridge include the Sig Sauer P320 or P229 Models as well as the Glock 32. Again, a more in-depth discussion of the smallest caliber 0.22 LR caliber pistol and its rimfiring system occurs later.

Table 2 Caliber information of pistols in the 102 mass shooting incidents (1999 2015)

\begin{tabular}{llllllll}
\hline Pistol (0.45) & Pistol (0.40) & Pistol (0.380) (Auto) & Pistol Sig (0.357) & Pistol (0.25) & Pistol (0.22 LR) & Pistol (9mm) & Total \\
\hline 16 & 13 & 7 & 1 & 3 & 5 & $33=$ Mode & 78 \\
\hline
\end{tabular}

\section{Summaries on revolvers in the mass shooting incidents}

A revolver is the other type of handgun with its cartridges (from 5 to 8 ) loaded in a rotating and swing-out or tip-up cylinder and is capable of firing in succession as many cartridges as these are loaded in the chamber in the cylinder before a reloading. The common calibers for revolvers are 0.44 Magnum, 0.38 Special, 0.357 Magnum, and $0.22 \mathrm{LR}$. The 0.38 Special revolver is the most frequently used revolver or the mode (7 times) and the next modal category is the 0.357 revolver (4 times) Table 3 .

Table 3 Caliber information of revolvers in the 102 mass shooting incidents (1999 20I5)

\begin{tabular}{lllll}
\hline Revolver (0.44) & Revolver (0.38) Special & Revolver (0.357) Magnum & Revolver (0.22 LR) & Total \\
\hline 3 & 7 = Mode & 4 & 2 & 16 \\
\hline
\end{tabular}




\section{Summaries on multiple types of firearms and locations in the mass shooting incidents}

It is also important to report the multiple types of firearms in each incident. Table 4 below presents the startling results in 30 incidents where two or more types of firearms were used in almost one-third of the total mass shooting cases (102 incidents). Table 5 summarizes several interesting findings. Contrary to public perception, the most frequent location (the mode) is the home of the victim (48 incidents), which supports the criminological theory that the most dangerous predator is amongst one's friends and acquaintances. Next, for public awareness purposes, it is very important to report the types of locations where these shooting incidents occurred. These other locations included:

1. Motel

2. Restaurant

3. Community center

4. Barber shop

5. Theater
6. Coffee shop
7. Hair salon
8. Pharmacy store
9. Marketplace
10. Television store
11. Hospital
12. City hall
13. Youth center
14. Hotel
15. Neighborhood, and
16. Hunting field.

Furthermore, the third modal category (12 times) was at school and university campuses, indicating safety and security measures must be a priority for school principals and university presidents.

Table 4 Numbers of types of firearms in the 102 mass shooting incidents (1999 2015)

\begin{tabular}{lllll}
\hline One Type & Two Types & Three Types & Four Types & Total \\
\hline $72=$ Mode & 20 & 6 & 4 & 102 \\
\hline
\end{tabular}

Table 5 Types of location information in the 102 mass shooting incidents (1999 20I5)

\begin{tabular}{lllllll}
\hline Military & Church & Workplace & School & Public & Home & Total \\
\hline $3(3 \%)$ & $3(3 \%)$ & $8(8 \%)$ & $12(12 \%)$ & $28(27 \%)$ & $\begin{array}{l}48=\text { Mode } \\
(47 \%)\end{array}$ & 102 \\
\hline
\end{tabular}

\section{Ballistic examinations and two image illustrations for the mass shooting incidents}

Once the ten relationships were established from the secondary data analysis and the fired cartridge cases collected, ballistic examinations were followed on the casing samples $(\mathrm{n}=16)$ using a stereo microscope in the author's forensic lab. The design features of each category of the fired casings collected were photographed. The following are the observational results of the ballistic examinations shown in Figures $1 \& 2$ with key words in italics to describe a particular category of fired cartridge case-firearm relationship. From a side view, figure 1 provides an image illustration of the ten categories of the case-firearm relationships that were identified from the 102 mass shooting incidents. The author presents the major findings in key words in italics and describes the ten categories of case-weapons associations for a quick determination:

1. No. 1 Shotgun Casing: All shotgun casings are much bigger in size than the rest of the casings and are usually made partially of plastics.

2. No. 2 Revolver Casing: All of the revolver casings have an outward rim at the base and no extraction groove, compared with the rimless pistol and rifle casings, which have an extraction groove.

3. No. 30.22 LR Casing: All the 0.22 LR casings are the smallest casing in size with a rim firing on the edge, instead of in the center for the rest of the casings (Figure 2).
4. No. 4 AR Rifle Casing: All the AR rifle casings ( 0.223 caliber) involved are bottle-necked shaped.

5. No. 5 AK Rifle Casing: All the AK 47 casings made in the U.S. also have a bottle-necked shape with both 7.62 and 39 at the bottom of the casing and are shorter and wider than the AR casing (Figure 2).

6. No. 6 Carbine Casing: All the 0.30 carbine casings have a cylinder shape (no bottle-necked) with a 0.30 at the bottom of the casing (Figure 1).

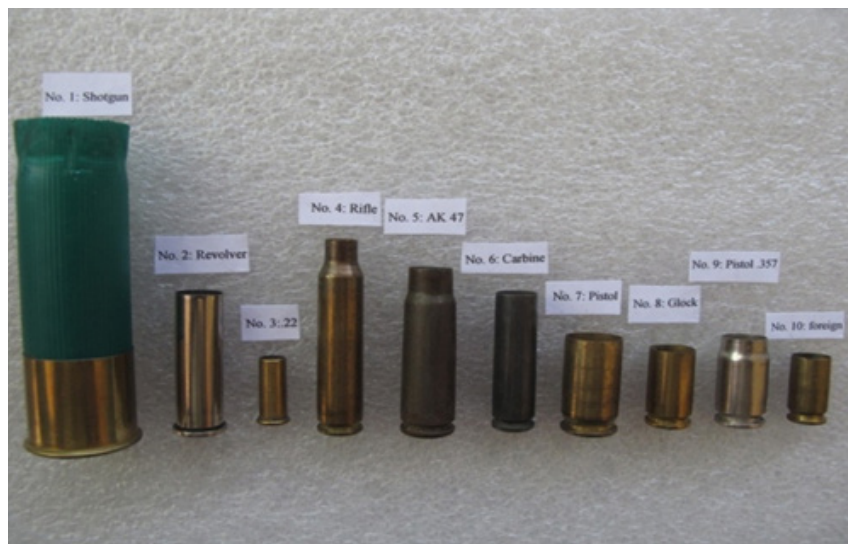

Figure I A side view of the ten types of fired casings associated with the 102 mass shooting incidents. 
7. No. 7 Pistol Casing: All the pistol casings are rimless and have an extraction groove with various caliber numbers at the bottom.

8. No. 8 Glock Casing: All the casings from the Glock pistol family possess a rectangular firing pin aperture mark. Among the 33 incidents of $9 \mathrm{~mm}$ pistol usage, many were of the Glock pistol family with this rectangular mark as a firing pin aperture impression (Figure 2).

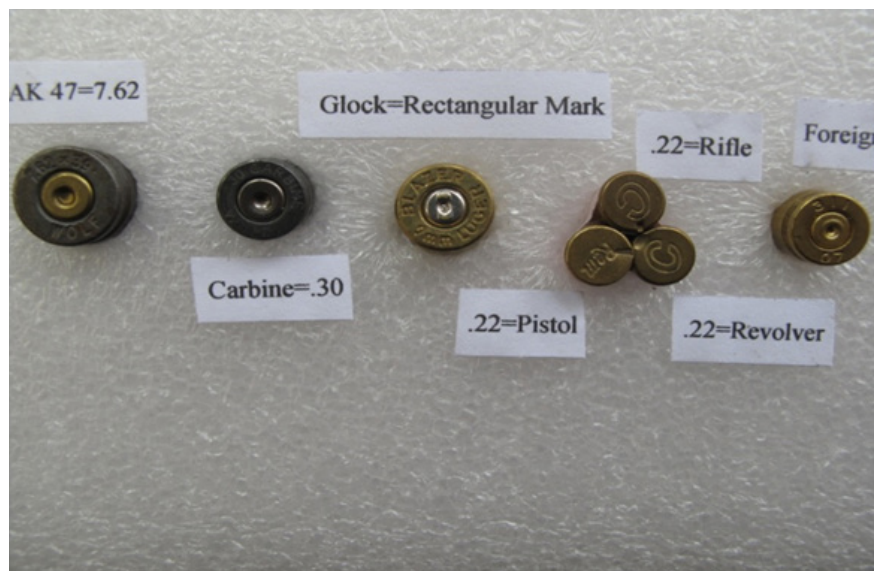

Figure 2 Head stamp and caliber information at the base of seven fired casings.

9. No. 90.357 Sig Pistol Casing: This is the only casing from the pistol family with a bottle-necked shape.

10. No. 10 Foreign Casing: During the collection process, another type of casing became known. Although it did not occur in the 102 sampled incidents, it could be a possibility in reality not included in the sampling: a foreign casing fired by using a foreign-made firearm that was possibly smuggled or imported legally into the U.S. Three ballistic design features observed were:

11. There may be no brand or manufactory information at the base of the casing

12. Two flash holes inside the casing, instead of one flash hole by the American manufactory, and More smoke residue on the exterior of the casing.

While Figure 1 presents the ten categories of the case-firearm relationships identified from a side view, Figure 2 provides the specific identification tips seen at the base of each casing. First, the AK 47 fired cases made in the U.S. follow a metric caliber system and always have the numbers $7.62 \times 39$ at the base of the cartridge. Second, the carbine casing is a thin cylinder with the number 0.30 at the base. Next, although the Glock factory in Austria produces 37 different models with different calibers, they all share one prominent ballistic feature: all of its firing pin aperture marks are a rectangular indentation within an oval firing pin indentation. Fourth, the $0.22 \mathrm{LR}$ cartridges (Long Rifle) are the smallest ammunition with a rim firing mechanism, meaning the firing pin mark is located on the edge of the base, instead of the center. While the 0.22 LR casing is the smallest one, it is most difficult to determine the types of firearms used to fire the cartridge. The $0.22 \mathrm{LR}$ is capable of being fired by either a rifle, a pistol, or a revolver and thus creates a challenge for a determination purpose in the field. While there may exist more fire pin patterns by
0.22 LR firearms, based on the preliminary ballistic examinations, the author argues $0.22 \mathrm{LR}$ rifle fired cases tends to have square and wedged marks while 0.22 LR pistol casings usually have rectangular and deeper indentations. The 0.22 LR revolver case, on the other hand, always has a circular firing pin mark. Luckily, revolver casings are not commonly present at crime scenes since the revolver does not eject the casings until the shooter reloads. Finally, the foreign made casing (depending on which country) shows three features:

a. The base of the casing has no English word to indicate the manufactory, which is required in the U.S. There are two flash holes inside the fired case, instead of one flash hole (American made).

b. The exterior casing wall usually has more visible gunpowder residues due to the poor quality of gunpowder.

Based on the design features and firearm-produced markings, the author contends that there exists a relationship between a fired cartridge case and corresponding ten categories of firearms in terms of casing materials, shapes, information at the base, firing mechanism, and firing pin impressions. As a result, the study generated two image illustrations of the ten categories of the fired cartridge case-firearm linkages with key words. Using the two image illustrations and the description discussed above, someone is able to identify or determine a category of firearm(s) by looking at a fired cartridge case(s) found at the scene.

\section{Discussion and conclusions}

Shooting incidents occur frequently at schoolyards, university campuses, workplaces, military facilities, community centers, neighborhoods, and clubs. An active shooting incident is a serious situation where a shooting is in progress and critical information such as the types or the category of firearms involved can affect the protocols in responding and reacting to the scene of the incident. The situation often inherently implies both law enforcement personnel and citizens have the potential to affect the outcome of the event based upon their responses..$^{10}$ In order to explore better counter-measures, a secondary data analysis was conducted to identify the most common types/category of firearms used in the mass shooting incidents (n =102) from 1999 to 2015 in the U.S. After the identification, the author went to several shooting ranges and gun stores to collect and purchase related fired cartridge cases. Finally, the author created two image illustrations to describe the relationship between certain ballistic design features of the fired cases and related types of firearms under discussion. Due to the fact that only one similar study was conducted in $1967,{ }^{11}$ this research study provides much more sufficient details in two educational image illustrations for law enforcement officers, responding officers, criminal investigators, crime scene technicians, teachers/students ( $\mathrm{K}$ to 12 and colleges), and the general public. This study may have greater implications:

a. To help law enforcement link possible weapons from fired cases more quickly

b. To assist crime scene technicians and investigators identify firearms involved, and

c. To educate the public, such as schoolteachers, students, and victims at an active shooting scene who may pass the information onto the police. In the near future, the author plans to design a special smart phone app (compatible with Android, iPhone, 
and Blackberry operating systems), which can automatically identify a specific type of firearms based on the image of the fired casing.

The practical values of this study lie in the possible situation: an individual looks at a fired cartridge cases at the scene and quickly is able to determine in less than one minute the corresponding type of firearms within the most common ten categories from this study. While this study did not intend to explore all facets of mass shooting incidents, its aim was to provide a fired cartridge case-firearm relationship and to assist law enforcement along with other first responders, corporations, educators, and the public to better deal with future tragic shooting incidents. It is important to realize that not only is an understanding of the threats faced necessary, but also the public awareness of quick identification tips available may help aid future handlings of shooting incidents.

\section{Acknowledgments}

None.

\section{Conflicts of interest}

None.

\section{References}

1. Gutierrez L. And now there are 52 school shootings in 2015: Arizona, Texas deaths brings toll to 28 .The Kansan City Star, USA. 2015.
2. Duclos M. An open letter to lawmakers after yet another mass shooting. Higher Education Advocate. 2015;33:16-17.

3. Mayors' Report, Analysis of recent mass shooting incidents. Crime Prevention Research Center, USA, 2015; p. 1-34.

4. Analysis of recent mass shootings from Mayors against Illegal Guns. Mayors Against Illegal Guns, USA, 2013; p. 1-35.

5. Luduc KL. Weapons used in mass shooting. Our Research report, USA. 2013.

6. Hagan EF, Mark LD. Research methods in criminal justice and criminology (13 ${ }^{\text {th }}$ edn). Pearson, USA, 2013; pp. 1-249.

7. Berg BL. Qualitative research methods for social sciences ( $7^{\text {th }}$ edn). Pearson, USA, 2007; pp. 1-352.

8. Bell S. The Facts on file dictionary of forensic science. Checkmark Books, USA, 2004; pp. 1-240.

9. Brenner C. Forensic science: An illustrated dictionary. CRP Press, USA, 2004; pp. 1-282.

10. Blair JP, Schweit KW. A study of active shooter incidents in 2000 and 2013. U.S. Department of Justice, USA, 2013; p. 1-47.

11. Erlemeier HA, Brandt JH. Manual of pistol and revolver cartridges. Hereward Books, UK, 1967; pp. 1-271. 